\title{
WORLD METEOROLOGICAL ORGANIZATION AND INTERNATIONAL SOCIETY OF BIOCLIMATOLOGY AND BIOMETEOROLOGY TO COLLABORATE
}

by

Frederick Sargent, II, M.D. (U.S.A.)

President I.S.B.B.

In June of this year the president of this Society received a letter from the Secretary-General of the World Meteorological Organization informing him that the Executive Committee of mo had, in Resolution 15 (EC-XI), directed the Secretary-General to (1) collaborate with this Society and (2) investigate the most proper and efficient manner in which bioclimatology and biometeorology of man may be integrated into the activities of wMo. The resolution, the letter from the Secretary-General to the President, and the President's reply are reproduced below.

Some comments on the background of this resolution may we of interest. Since the formal founding of this Society in August, 1956, at UNESCO H.Q. in Paris excellent relations have been maintained with WMO. Observers from WMo have attended the congresses of I.S.B.B. and likewise observers from I.S.B.B. have attended the meetings of the Commissions on Climatology and Agricultural Meteorology. At the 2nd Congress of the Commission on Climatology, Washington, D.C., Jauuary, 1957, the president of I.S.B.B. urged WMO to collaborate with I.S.B.B. This Society could act in an advisory capacity and keep WMO informed on current developments in bioclimatology and biometeorology. Similar suggestiong have been made by Mr. P.M.A. Bourke at mure recent metings of the Commission on Agricultural Meteorology at Warsaw and Geneva and by the Secretary -General of I.S.B.B. at the recent world conference of W.M.0. j.tself at Geneva. Now these suggestions have born fruit. Just what form the collaboration will finally take cannot be foretold.

The aims of the Executive Board are to integrate the efforts of the many un agencies engaged or interested in bioclimatology and biometeorology, to avoid unnecessary duplication of work, and encourage closer collaboration among these agencies. It may be noted in this regard that progress is also being made toward active collaboration with the World Health Organization. The Board hopes to be able to report further developments along these lines by September, 1960 . 